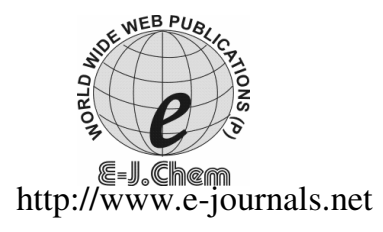

ISSN: 0973-4945; CODEN ECJHAO

E-Journal of Chemistry 2009, 6(S1), S358-S362

\title{
Multicomponent One-Pot Synthesis of Substituted Hantzsch Thiazole Derivatives Under Solvent Free Conditions
}

\author{
BHASKAR S. DAWANE ${ }^{\# *}$, SHANKARAIAH G. KONDA\#, VINOD T. KAMBLE, \\ SANJAY A. CHAVAN ${ }^{\S}$, RAGHUNATH B. BHOSALE ${ }^{\#}$ and SHAIKH BASEER M
}

Department of Chemistry, ${ }^{\#}$ Organic Research Laboratory, Yeshwant Mahavidyalaya, Nanded-431602 (M.S), India.

School of chemical sciences, Swami Ramanad Teerth Marathwada University, Vishnupuri, Nanded-05 (M.S), India.

${ }^{\S}$ Gopikishan Sitaram Gawande Science College, Umarkhed. (M.S), India. bhaskardawane@rediffmail.com

Received 3 May 2009; Accepted 1 July 2009

\begin{abstract}
Thiazole derivatives were prepared by one-pot procedure by the reaction of $\alpha$-haloketones, thiourea and substituted $o$-hydroxybenzaldehyde under environmentally solvent free conditions.
\end{abstract}

Keywords: $\alpha$-Haloketones, Thiourea, Substituted $o$-hydroxy benzaldehydes, Solvent free condition.

\section{Introduction}

Thiazoles are important class of natural and synthetic compounds. Thiazole derivatives display a wide range of biological activities such as cardiotonic ${ }^{1}$, fungicidal ${ }^{2}$, sedative ${ }^{3}$, anasthetic $^{4}$, bactericidal ${ }^{5}$ and anti-inflammatory ${ }^{6}$. The synthesis of thiazole derivatives is important of their wide range of pharmaceutical and biological properties. The most straight forward procedure reported by Hantzsch in 1887 involves one-pot condensation of $\alpha$ haloketones, and thiourea or thioamides in refluxing alcohol ${ }^{7}$. This is method, however long reaction time $(24-25 \mathrm{~h})$, harsh reaction conditions, the use of large quantity of volatile organic solvents generally gives low yields .Modified procedures have been reported by King $e t a l^{8 \mathrm{a}-\mathrm{b}}$ and others ${ }^{9 \mathrm{a}-\mathrm{d}}$ involving the replacement of $\alpha$-haloketones with ketones and halogen. Despite this modification the methods of King et al. and others are cumbersome and required long reaction time (24-25 h). Therefore, the development of more economical and environmentally friendly conversion processes is highly desirable. 
With the increasing environmental concern and the regulatory constraints faced in the chemical and pharmaceutical industries, development of environmentally benign organic reactions has become a crucial and demanding research area in modern organic chemical research ${ }^{10}$. Therefore, more and more chemists synthetic endeavors are devoted towards 'green synthesis' which means the reagent, solvent and catalyst are environmentally friendly. In modern organic chemical research, Wender defined the 'ideal synthesis' as one in which the target components are produced in one-step, in quantitative yield from readily available and inexpensive starting materials in resource effective and environmentally acceptable process ${ }^{11}$. Multicomponent condensations represent a possible instrument to perform near ideal synthesis because they possess one of the aforementioned qualities, namely the possibility of building up complexing molecules with maximum simplicity and brevity.

In recent years, to minimize the amount of harmful organic solvents used in chemical processes, much attention has been devoted to the use of alternative reaction media ${ }^{12 \mathrm{a}}$. Besides the use of supercritical fluids, water and ionic liquids, the possibility of performing chemical processes in the absence of solvent (solvent free) conditions has been receiving more attention ${ }^{2 \mathrm{~b}-13}$. The reported examples demonstrate that no solvent reactions are generally faster, gives higher selectively and yields, and usually require easier work up procedures and simpler equipments ${ }^{13-14}$.

\section{Experimental}

Melting points were determined by in open capillary method and are uncorrected. The chemicals and solvents used for laboratory grade and were purified. IR spectra were recorded (in $\mathrm{KBr}$ pallets) on SCHIMADZU spectrophotometer. ${ }^{1} \mathrm{H}$ NMR spectra were recorded (in DMSO- $d_{6}$ ) on AVANCE-300 MHz spectrometer using TMS as an internal standard. The mass were recorded on EI-SHIMDZU-GC-MS spectrometer. Elemental analyses were performed on a Perkins-Elmer CHN elemental analyzer.

General procedure for synthesis of 2-\{[4-sub.phenyl)-thiazol-2-yl-imino]-methyl\}phenol (4a-j)

\section{Method A}

A mixture of 2'-hydroxy-5' chloro- $\alpha$-haloketones (1) (1 mmol), thiourea (2) (1 m mol) and $o$-hydroxybenzaldehyde (3) in ethanol was refluxed for $5 \mathrm{~h}$. The reaction mixture was cooled at room temperature, poured on crushed ice $(20 \mathrm{~g})$. The separated solid was filtered, washed with ice cold water and recrystallized from aqueous acetic acid to give product (4).

\section{Method B}

A mixture of 2'-hydroxy-5'chloro- $\alpha$-haloketones (1) (1 m mole) and thiourea (2) (1 mmol) wetted with 2-4 drops of ethanol, followed by $o$-hydroxybenzaldehyde (3) (1 mmol) was grinded by pestle in mortar at room temperature for the period as shown in Table 1. The progress of reaction was monitored by TLC. After completion of reaction solid product thus obtained was poured on crushed ice $(20 \mathrm{~g})$. The separated product was filtered washed with ice cold water and recrystalized from $5 \%$ aqueous acetic acid $(6 \mathrm{~mL})$ to afford to the pure product (4).

\section{Spectroscopic data of selected compounds}

4a: IR (KBr): 3226, $3118(-\mathrm{OH}), 1611(-\mathrm{C}=\mathrm{N}) \mathrm{cm}^{-1} ;{ }^{1} \mathrm{H}$ NMR (DMSO- $\left.d_{6}\right): \delta 6.72-7.85(\mathrm{~m}$, $8 \mathrm{H}, \mathrm{Ar}-\mathrm{H}+5 \mathrm{H}$ of thiazole $), \delta 8.26\left(\mathrm{~s}, 1 \mathrm{H}\right.$, azomethine), $\delta 10.62\left(\mathrm{~s}, 1 \mathrm{H}, \mathrm{OH}, \mathrm{D}_{2} \mathrm{O}\right.$ exchangeable), $\delta 12.21$ (s, $1 \mathrm{H}, \mathrm{OH}, \mathrm{D}_{2} \mathrm{O}$ exchangeable) ppm; Anal. Calcd for $\mathrm{C}_{16} \mathrm{H}_{11} \mathrm{O}_{2} \mathrm{~N}_{2} \mathrm{SCl}$ : C, 58.11; H, 3.32; N, 8.46\%. Found: C, 58.28; H, 3.18; N, 8.34\%. 
4b: IR (KBr): 3241, $3130(-\mathrm{OH}), 1609.45(-\mathrm{C}=\mathrm{N}) \mathrm{cm}^{-1} ;{ }^{1} \mathrm{H}$ NMR (DMSO- $\left.d_{6}\right): \delta 6.78-$ $7.98(\mathrm{~m}, 7 \mathrm{H}, \mathrm{Ar}-\mathrm{H}+5 \mathrm{H}$ of thiazole $), \delta 8.21(\mathrm{~s}, 1 \mathrm{H}$, azomethine $), \delta 11.18\left(\mathrm{~s}, 1 \mathrm{H}, \mathrm{OH}, \mathrm{D}_{2} \mathrm{O}\right.$ exchangeable), $\delta 12.42\left(\mathrm{~s}, \quad 1 \mathrm{H}, \quad \mathrm{OH}, \quad \mathrm{D}_{2} \mathrm{O}\right.$ exchangeable)ppm; Anal. Calcd for $\mathrm{C}_{16} \mathrm{H}_{10} \mathrm{O}_{2} \mathrm{~N}_{2} \mathrm{SClBr}$ : C, 46.91; H, 2.44; N, 6.83\%. Found: C, 46.99; H, 2.28; N, 6.72\%.

4d: IR (KBr): 3216, $3098(-\mathrm{OH}), 1613(-\mathrm{C}=\mathrm{N}) \mathrm{cm}^{-1} ;{ }^{1} \mathrm{H}$ NMR (DMSO- $\left.d_{6}\right): \delta 2.34(\mathrm{~s}$, $\left.3 \mathrm{H}, \mathrm{CH}_{3}\right), \delta 6.98-8.06(\mathrm{~m}, 7 \mathrm{H}, \mathrm{Ar}-\mathrm{H}+5 \mathrm{H}$ of thiazole), $\delta 8.22(\mathrm{~s}, 1 \mathrm{H}$, azomethine), $\delta 10.72$ (s, $1 \mathrm{H}, \mathrm{OH}, \mathrm{D}_{2} \mathrm{O}$ exchangeable), $\delta 11.98\left(\mathrm{~s}, 1 \mathrm{H}, \mathrm{OH}, \mathrm{D}_{2} \mathrm{O}\right.$ exchangeable)ppm; Anal. Calcd for $\mathrm{C}_{17} \mathrm{H}_{13} \mathrm{O}_{2} \mathrm{~N}_{2} \mathrm{SCl}$ : C, 59.27, H, 3.77; N, 8.12\%. Found: C, 59.12; H, 3.88; N, 8.23\%.

4g: IR (KBr): 3230, $3256(-\mathrm{OH}), 1611(-\mathrm{C}=\mathrm{N}) \mathrm{cm}^{-1} ;{ }^{1} \mathrm{H}$ NMR (DMSO- $\left.d_{6}\right): \delta$ 7.02-8.11 $(\mathrm{m}, 7 \mathrm{H}, \mathrm{Ar}-\mathrm{H}+5 \mathrm{H}$ of thiazole $), \delta 8.21(\mathrm{~s}, 1 \mathrm{H}$, azomethine $), \delta 10.78\left(\mathrm{~s}, 1 \mathrm{H}, \mathrm{OH}, \mathrm{D}_{2} \mathrm{O}\right.$ exchangeable), $\delta 12.16\left(\mathrm{~s}, \quad 1 \mathrm{H}, \quad \mathrm{OH}, \quad \mathrm{D}_{2} \mathrm{O}\right.$ exchangeable)ppm; Anal. Calcd for $\mathrm{C}_{16} \mathrm{H}_{10} \mathrm{O}_{2} \mathrm{~N}_{2} \mathrm{SCl} 2$ : C, 52.63, H, 2.73; N, 7.66\%. Found: C, 52.72; H, 2.64; N, 7.81\%.

\section{Results and Discussion}

In view of the recent emphasis aimed at developing new selective and environmentally friendly methodologies for the preparation of fine chemicals, herein we report expeditious synthesis of substituted 2-\{[4-sub.phenyl)-thiazol-2-yl-imino]-methyl\}-phenol by the onepot condensation of $\alpha$-haloketones, thiourea and substituted $o$-hydroxybenzaldehyde under environmentally solvent-free conditions (Scheme 1).

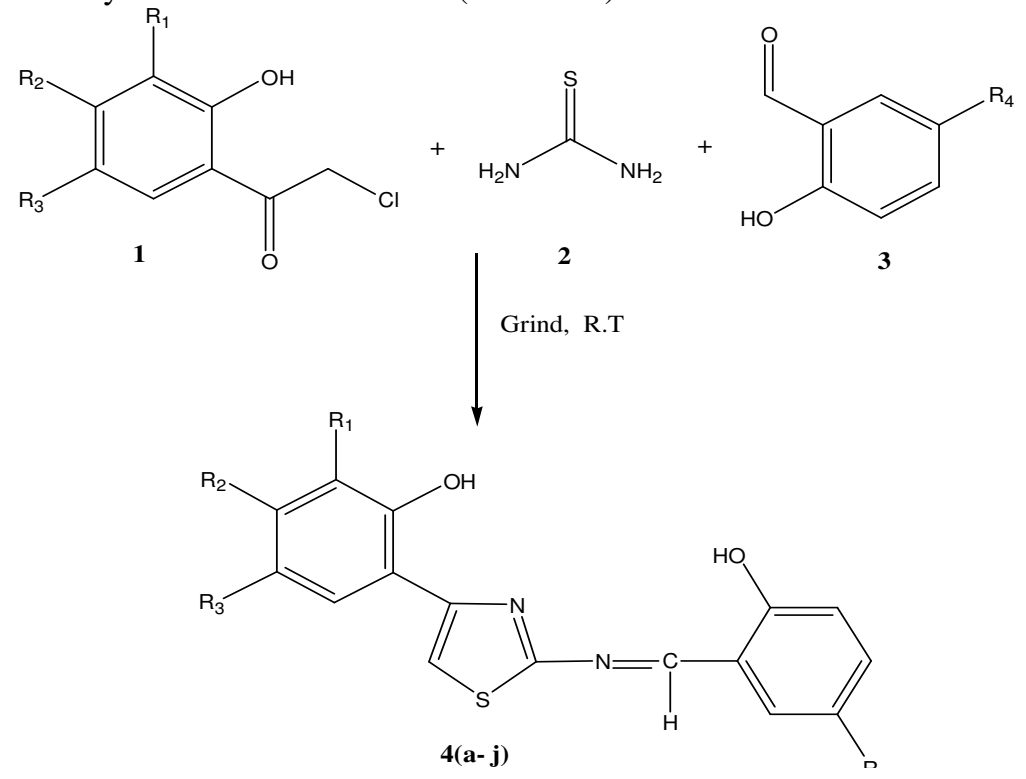

\section{Scheme 1}

Initially, we attempted the one-pot condensation of 2'-hydroxy- 5'-chloro- $\alpha$-haloketone, thiourea and $o$-hydroxybenzaldehyde under solvent free condition. The reaction went to completion within 3 minutes and the corresponding product was obtained in $95 \%$ yield. Encouraged by the results obtained with $o$-hydroxybenzaldehyde, thiourea and 2 '-hydroxy-5'-chloro- $\alpha$-haloketone, we turned our attention to variety of $o$ hydroxybenzaldehydes and 2'-hydroxy substituted- $\alpha$-haloketones respectively. Interestingly, various $o$-hydroxybenzaldehydes and 2'-hydroxy-substituted- $\alpha$-haloketone reacted smoothly with thiourea under solvent free conditions to give the corresponding thiazole 
derivatives in $85-95 \%$ yield. In all cases, the reaction proceeded efficiently in high yield at room temperature under solvent-less conditions. All the products were characterized by IR, ${ }^{1} \mathrm{H}$ NMR and MASS spectral analysis.

When attempts were made to carry out the synthesis of thiazole derivatives by classical method in ethanol under reflux temperature, the yield of the products are poor $(60-70 \%)$. In general, reactions under solvent-free condition are clean, rapid and afforded higher yield than those obtained by conventional method. The results of the reactions under solvent-free conditions are compared with reflux condition and short reaction times were observed, which is more economy in terms of times, enhanced reaction rates, improved yields and high selectivity are the features obtained in solvent free conditions. The scope and generality of this process is illustrated with respect to various $o$-hydroxybezaldehyde and 2'-hydroxy substituted- $\alpha$-haloketones and the result are presented in Table 1.

Table 1. Synthesis of Hantzsch thiazole derivatives under solvent free conditions.

\begin{tabular}{cccccccccc}
\hline \multirow{2}{*}{ Product } & \multicolumn{4}{c}{ Substitutions } & \multicolumn{3}{c}{ Method A } & \multicolumn{2}{c}{ Method B $_{n}^{*}$ M.P $^{\circ} \mathrm{C}$} \\
\cline { 2 - 8 } & $\mathrm{R}_{1}$ & $\mathrm{R}_{2}$ & $\mathrm{R}_{3}$ & $\mathrm{R}_{4}$ & Time $^{\mathrm{a}}$ & Yield $^{\mathrm{c}}, \%$ & Time $^{\mathrm{b}}$ & Yield $^{\mathrm{c}}, \%$ & \\
$4 \mathrm{a}$ & $\mathrm{H}$ & $\mathrm{H}$ & $\mathrm{Cl}$ & $\mathrm{H}$ & 5 & 64 & 3 & 95 & 182 \\
$4 \mathrm{~b}$ & $\mathrm{Br}$ & $\mathrm{H}$ & $\mathrm{Cl}$ & $\mathrm{H}$ & 5 & 62 & 3 & 92 & 148 \\
$4 \mathrm{c}$ & $\mathrm{I}$ & $\mathrm{H}$ & $\mathrm{Cl}$ & $\mathrm{H}$ & 5 & 65 & 5 & 91 & 195 \\
$4 \mathrm{~d}$ & $\mathrm{H}$ & $\mathrm{CH}_{3}$ & $\mathrm{Cl}$ & $\mathrm{H}$ & 5 & 62 & 5 & 88 & 132 \\
$4 \mathrm{e}$ & $\mathrm{H}$ & $\mathrm{H}$ & $\mathrm{CH}_{3}$ & $\mathrm{H}$ & 4.5 & 66 & 8 & 92 & 156 \\
$4 \mathrm{f}$ & $\mathrm{Br}$ & $\mathrm{H}$ & $\mathrm{CH}_{3}$ & $\mathrm{H}$ & 5 & 68 & 5 & 90 & 183 \\
$4 \mathrm{~g}$ & $\mathrm{H}$ & $\mathrm{H}$ & $\mathrm{Cl}$ & $\mathrm{Cl}$ & 4.5 & 64 & 3 & 91 & 140 \\
$4 \mathrm{~h}$ & $\mathrm{H}$ & $\mathrm{CH}$ & $\mathrm{Cl}$ & $\mathrm{Cl}$ & 4 & 65 & 5 & 89 & 128 \\
$4 \mathrm{i}$ & $\mathrm{H}$ & $\mathrm{H}$ & $\mathrm{CH}$ & $\mathrm{Cl}$ & 4 & 65 & 8 & 92 & 162 \\
$4 \mathrm{j}$ & $\mathrm{Br}$ & $\mathrm{H}$ & $\mathrm{Cl}$ & $\mathrm{Cl}$ & 5 & 62 & 5 & 90 & 138 \\
\hline
\end{tabular}

${ }^{a}$ Time in hours based on Method A, ${ }^{b}$ Time in minutes Method B ${ }^{c}$ Pure isolated yield of products.

\section{Conclusion}

In summary, we have developed a simple, convenient and effective method for easy synthesis of thiazole derivatives by the condensation of $o$-hydroxybenzaldehyde, 2'-hydroxy substituted $-\alpha$-haloketones and thiourea under solvent free conditions. Present methodology offers very attractive features such as reduced reaction times, higher yields and environmentally benign condition. The simple procedure combined with ease of work-up and entirely solvent-free conditions make this method economic, benign and a waste-free chemical process for the synthesis of thiazole derivatives of biological importance. Thus, we believe that this green procedure will be worthwhile addition to the present methodologies. To our knowledge, this is the first time report of an efficient general method for the synthesis of thiazole derivatives by using various 2 '-hydroxy substituted- $\alpha$-haloketones as one of the substrate.

\section{Acknowledgements}

The authors are sincerely thankful to Principal, Yeshwant Mahavidyalya, Nanded for providing Laboratory facilities. One of the author (SAC) is thankful to the UGC for award of teacher fellowship. 


\section{References}

1. $\quad$ Suri K A, Suri O P and Atal C K, Indian Drug, 1980, 23(4), 207.

2. $\quad$ Tripati H and Mahapatra S N, J Indian Chem Soc., 1975, 52(8), 766.

3. Louis L, Eur Pat, 263, 020, Chem Abstr., 1998, 109, 128995q.

4. Geronikaki A and Theophilidis, Eur J Med Chem., 1992, 27(7), 709; Chem Abstr., 1993, 118, 147501C.

5. Mean R G N and Mocoelo C R O, Afinidad, 1993, 50(447), 319; Chem Abstr., 1994, 120, 244806 e.

6. Giridhar T, Reddy R B, Prasanna B and Chandra Mouli G V P, Indian J Chem., 2001, 40B, 1279.

7. Hantzsch and Weber H J, Ber Dtsch Chem Ges., 1987, 20, 3118.

8. (a) Dadson R M and King L C, J Am Chem Soc., 1945, 67, 2242; (b) King L C and Hlavacck R J, J Am Chem Soc., 1950, 72, 3722.

9 (a) Rajeshwar Rao V and Padmanabha Rao T V, Indian J Chem., 1986, 25B, 413;

(b) Rajeshwar Rao V, Rao M S and Padmanabha Rao T V, Collect Czech Chem Comm., 1986, 51, 2214; (c) Aditya Vardhan V and Rajeshwar Rao V, Indian J Chem., 1997, 36B, 1085; (d) Rajeshwar Rao V, Mohan G, Ravi Kumar V and Aditya Vardhan V, Phasphorus, Sulfur and Silicon and the Related Elements, 1996, 47, 113.

10 Anastas $\mathrm{P}$ and Wiliamson T, Green Chemistry, Frontiers In Benign Chemical Synthesis and Procedures: Oxford Science Publications, Oxford, 1998.

11 Wender P A, Handy S L and Wright D L, Chem Ind (London), 1997, 765.

12 (a) Jundo $\mathrm{P}$ and Anastas $\mathrm{P} \mathrm{T}$, Green Chemistry: Theory and Practice; Oxford University Press: Oxford, 1998; (b) Desimone J M, Science, 2002, 297, 799.

13 (a) Metzger J O, Angew Chem Int Ed., 1998, 37, 2975; (b) Varma R S, Green Chemistry, 1993, 43; (c) Janaka K and Toda F, Chem Rev., 2000, 100, 1025; (d) Varma R S, Pure Appl Chem., 2001, 73, 193; (e) Cave G W V and Raston, Scott J L, Chem Commun., 2001, 2159; (f) Tanaka K and Toda F, Solvent Free Organic Synthesis, Willey-VCH, 2003

14 (a) Loh P T, Huang M J, Goh S H and Vittal J J, Org Lett., 2002, 2, 1291; (b) Hajipoor A R, Arbabian M and Ruoho A E, J Org Chem., 2002, 67, 8622; (c) Yadav L D S and Singh S, Synthesis, 2003, 63; (d) Lee J C and Bae Y H, Synlett., 2003, 564. 


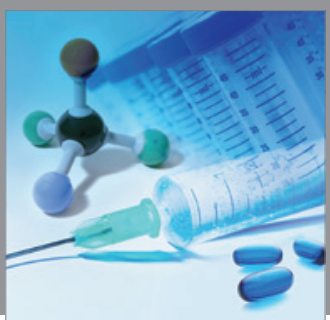

International Journal of

Medicinal Chemistry

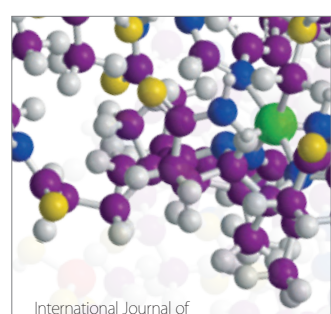

Carbohydrate Chemistry

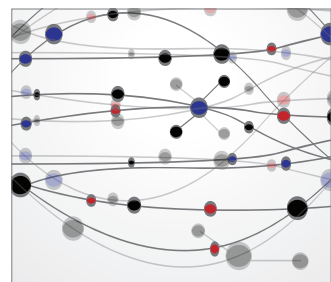

The Scientific World Journal
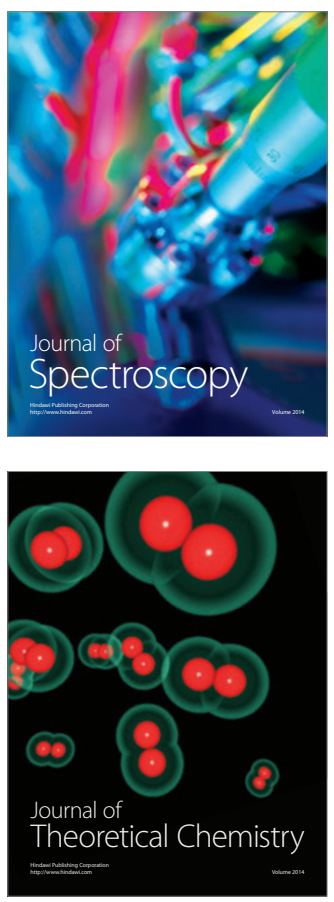
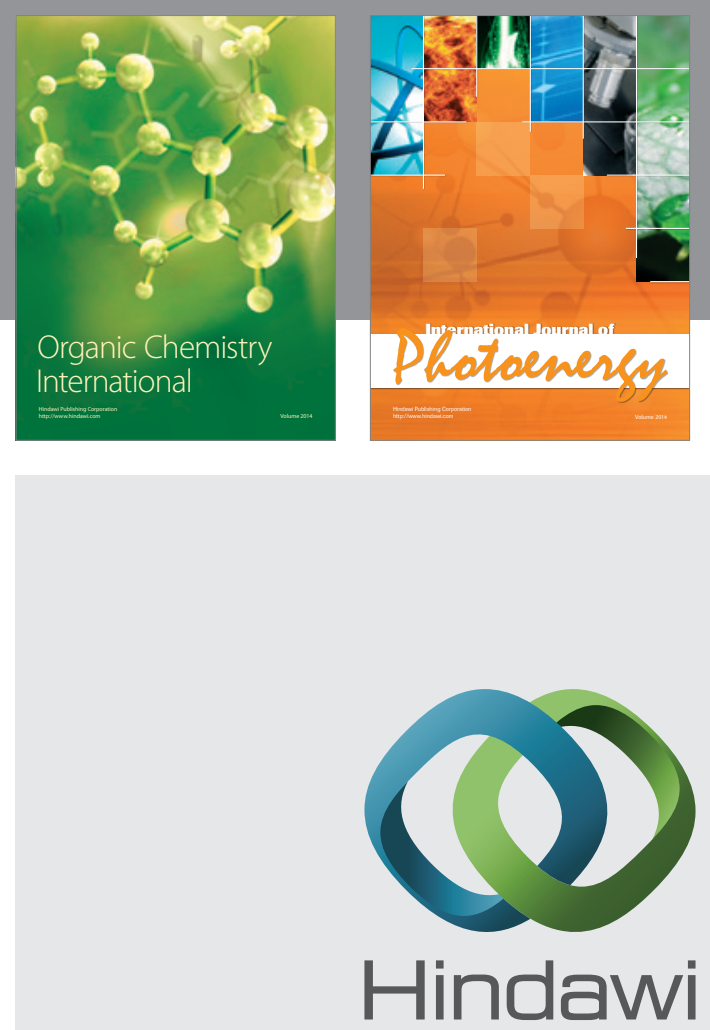

Submit your manuscripts at

http://www.hindawi.com
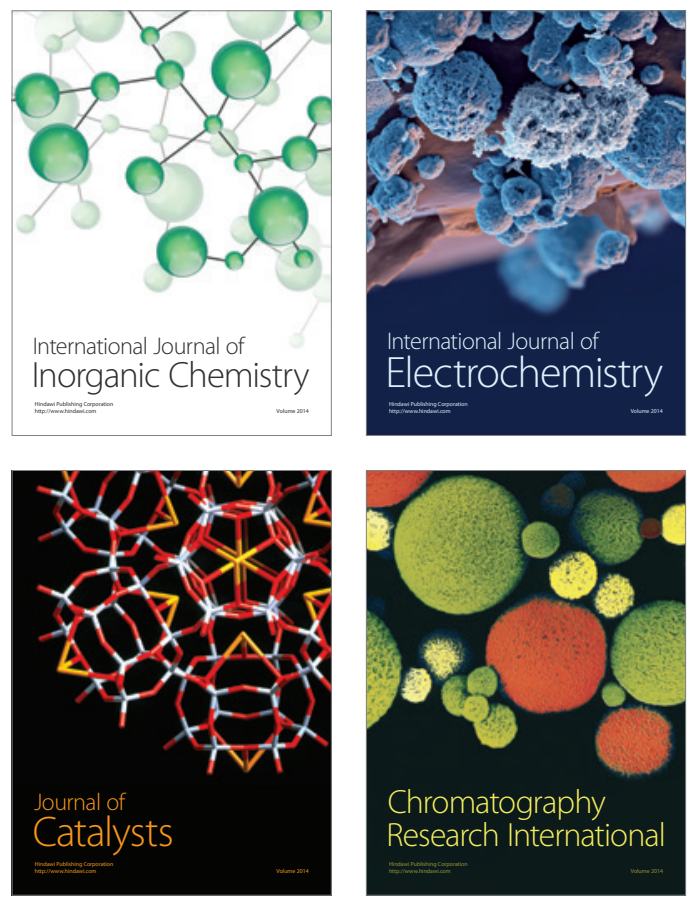
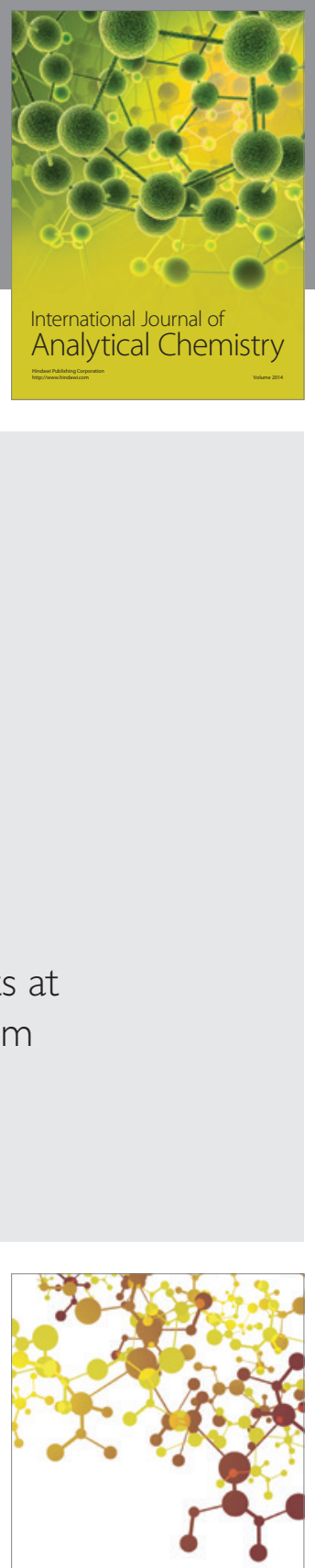

Journal of

Applied Chemistry
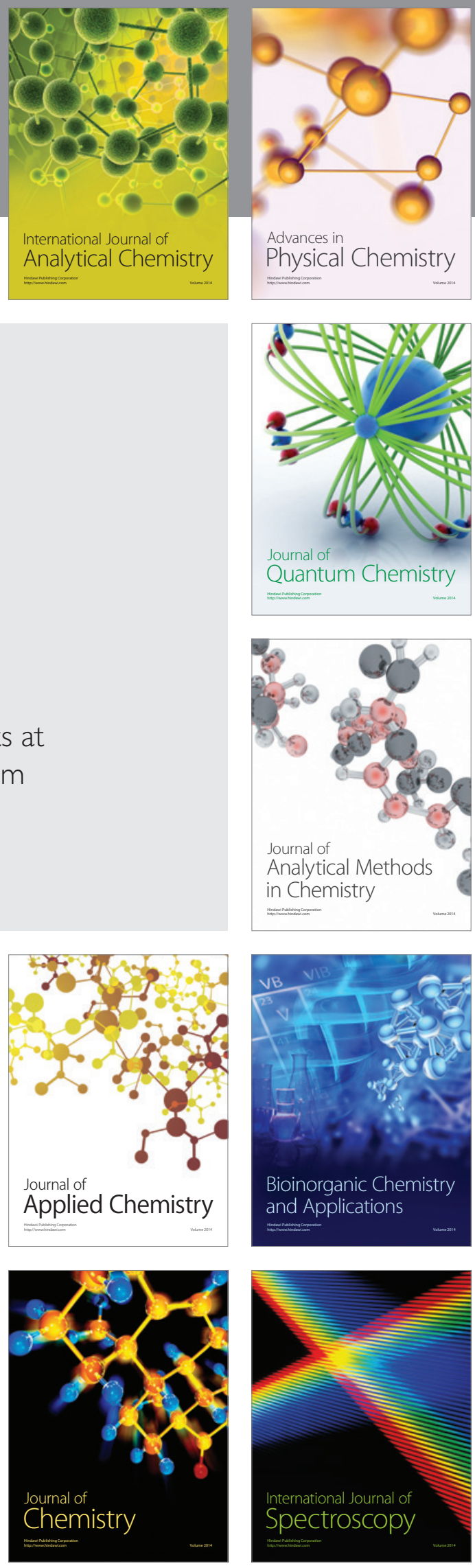